\title{
1 Phenomenology of Positive Change: Social Growth
}

\begin{abstract}
This chapter exposes the theoretical background of Flow of Consciousness Theory, underlining the connections between Optimal Experience and the process of social change. The concept of cultural artifact is revised. The relevance of Flow for the individual, social and cultural development is stressed. Discussion is devoted to letting the presence of the experience of flow emerge (both explicitly admitted or implicitly assumed) within theories and models not belonging to Positive Psychology domain.
\end{abstract}

Keywords: Cultural artifacts; Cultural change; Flow of consciousness; Theoretical implications.

\subsection{Introduction}

A mother, in the United States of America, is playing with her daughter in the living room; a Chinese father is on his way to enroll his child in school; an Italian worker is walking into the factory; an Iranian young man is planning an evening with his friends; a Filipino girl is dancing with her friends at a disco; a Brazilian elderly man is praying in a church. Our daily life, all over the world, flows, characterized by thoughts and emotions, in various contexts of our culture, in the places we go to, among the groups that surround us and to which we belong. Psychological sciences have long since been studying the mechanisms of this complex interaction between the inner and the social world. The so-called Cultural Psychology (Cole, 1996; Inghilleri, 2009; Shweder, 1991) and the so-called Positive Psychology (Kahneman, Diener \& Shwarz, 1999; Seligman \& Csikszentmihalyi, 2000) have, in recent years, developed and highlighted a direction of research not altogether new in the behavioral sciences, namely the need to study humans in their real-life contexts (rather than in laboratory) and to develop interpretative models starting from the study not of pathological situations but of virtuous situations and situations of development.

At the basis of this theoretical approach, which finds its roots in the early pioneering work of William James (1890), is a vision according to which the individual actively builds their own identity and does so in a harmonious way with the context, starting from their own biological basis and through their interaction with the culture. The inner Self is achieved by way of cognitions, motivations, and affections occurring in the course of everyday life, as well as through specific experiences. The 
quality of subjective experience is central for the construction of the personal Self and of personal behavior. The way we feel is related to a variety of causes: to our past; to the immediate experience; to the ability to connect the immediate experience with our intentions, our profound purposes, our own individual projects. It is therefore important that the relationship between the past, present and future be orderly and complex. The focus of our knowledge and of our affections thus depends on the possibility that a specific mind/culture relationship provides an experience that the subject perceives as making sense and being organized insofar as it is connected to the existing situation, to the core of personal identity (which derives from past experience), to future purposes.

In this sense, the concept of subjective experience appears central. It may be defined as the sum of the information, originating either from the outer world or the inner world, which enters in the psychic system at a given point in time and its comprehensive interpretation by the consciousness. More precisely experience is meant as the focusing of the process of attention on the interrelationships of the data in the consciousness or, in other words, the set of cognitive, motivational and emotional information capable of producing discriminable changes (and therefore selectable by the attention) in our subjective state. For Csikszentmihalyi (1982, 1988), the focus on the interrelationship of the data in the consciousness produces experience. This is an orderly process that requires energy. The consciousness becomes disordered when the information entered is either too simple or too complex. This may be due to either external factors (environment contains too many or too few stimuli) or to the malfunction of the processes of attention that allow excessive or insufficient information to reach consciousness. This conceptualization is important because it highlights how psychological processes (consciousness, attention, emotions) and cultural processes (social environment, the others) are part of a single system which the inner state of the individual and its development depend on. In other words it is not possible to understand the psychological functions without considering the external culture as well.

\subsection{Cultural Evolution and Individual Psychological Selection}

In the first place, it must be emphasized that the relationship between the individual and culture gives rise to two processes that interact while being distinct from each other: the Cultural evolution and the Individual psychological selection (Inghilleri, 1999).

The Cultural evolution is a historical cross-generational process (i.e. passing from one generation to another) for the transmission of cultural information stored in extra-individual locations, that is in the products (or artifacts) of culture. The Individual psychological selection, on the other hand, is a process that relates to the single individual, therefore lasting a lifetime, and represents the selective internalization in the central nervous system of a part of the external cultural information. 
This internalization is associated with elaboration processes, construction of meanings, and affective experience (Delle Fave, Massimini \& Bassi, 2011). We could say that the different theories of individual psychology have historically sought to define the mechanisms of the psychological selection. Of utmost importance, though not always considered by the various psychological theories, is that cultural evolution and psychological selection are in a continuous relationship of reciprocal causality, in the sense that one influences the other. Culture, as it is realized, in a certain context and at a particular historical period, co-determines (Markus \& Kitayama, 1991) the construction of the individual Self (think for example of all the educational and socialization activities): but it is the actions of individuals, their decision-making processes, the focus of attention and of behavior on certain purposes, the experiences and the emotions that make the different areas of our lives attractive or unpleasant, that cause certain elements of culture, and not others, to be transmitted in time.

\subsection{The Artifacts and Their Relationship with the Subjective Experience}

Secondly, referring to authors such as Vygotsky (1978), Bruner (1990) or the aforementioned Cole and Shweder, a basic concept will be discussed that has characterized those authors and that is particularly interesting in the understanding of the mechanisms of psychological selection: the concept of artifact.

The term artifact has been widely used in cultural psychology: it defines any entity not present in nature but constructed or produced by human beings. Artifacts are therefore the very constituents of the cultures. The category of artifact thus includes objects (such as the furniture in a house, clothes, a car, a flag), material structures (such as buildings or a city district), as well as ideas, artistic products such as music or poetry, technologies, institutions, political views, religions, rituals, daily practices, and so on. It concerns therefore both tangible and intangible entities.

Artifacts are key elements from the point of view of the relationship between individual psychological processes and culture, by reason of a number of characteristics. They have in fact a double status: they are in an intermediate situation between the world of the "living" and the world of the "non-living" (Monod, 1971). To explain this property of the artifacts, the following discussion involves a closer examination of some features of the living world that may be pertinent, as we shall see, to the artifacts.

In 1971, Jacques Monod, a molecular biologist who was awarded the 1965 Nobel Prize for Medicine, highlighted the three general traits by reason of which the living organisms are, as a whole, different from any other entity in this universe.

The first characteristic is the so-called teleonomy, according to which living organisms are entities with a project, which is represented in their structures and at the same time realized through their actions. Consider the genetic information contained in the DNA of the first zygote of the embryo, the result of the union of ovule and 
sperm: it represents the project that will be manifested in the structure of the whole adult organism and will be realized through its operations.

The second characteristic is the autonomous morphogenesis, the living organism is a "machine that builds itself", does not depend on forces applied from the outside, but has an autonomous determinism implying a virtually total freedom with respect to outside agents or conditions, which are capable of impeding this development, as well as guiding it (Monod, 1971).

The third characteristic is the so-called reproductive invariance which is the ability to reproduce and transmit unchanged the information corresponding to the structure (the genetic heritage). The genes are in fact a highly complex organization that manages to be preserved in its entirety from one generation to the other.

To continue our reasoning about the properties of artifacts it is necessary, at this point, to introduce another concept, namely the distinction between entropy and negative entropy or negentropy. The physical, inorganic world, the so-called "non-living nature" (i.e. the material of which many artifacts of our everyday lives are made of, such as objects of domestic use or a building) follows the second law of thermodynamics, in other words tends to entropy. This principle states that each energetically isolated system evolves in a single direction, that of the degradation of the order that characterizes it. It follows a specific relationship between entropy and information: the more a system is entropic, the less information is present (Monod, 1971). In concrete terms, the second law of thermodynamics can be exemplified by the following case: if we leave an artifact in the open air under the influence of atmospheric agents, after a certain time it will disintegrate and turn into rust, dust, inert matter: that artifact, abandoned, without maintenance, undergoes a process of entropy, losing order and information.

On the other hand, historical theorists of complexity, such as Miller (1970) and Prigogine (1976), have long since shown that living systems tend, instead, to negative entropy (or negentropy), namely to heterogeneity, to the progressive complexity of structures, to the continuous differentiation of functions.

The artifacts, as non-living entities, are therefore per se devoid of autonomous morphogenesis and self-organization; they are subject to the second law of thermodynamics and therefore tend to disorder, to homogenization, to the loss of information, to entropy: if an object is not kept with care, in time this artifact will be ruined, and gradually disintegrate.

There is one further point in this reasoning. The artifacts are the result of the application, to the materials that constitute them, of outside forces originated by the author, that is, from the living world, from human beings: men and women who decide to create artifacts, to give them a meaning, to transmit or modify them. Artifacts therefore are a reflex of and can accept the trend towards complexity, organization, order and information typical of the living world itself, that is to say, proper to the people who choose them, use them and give them meaning. Hence they can also tend to negentropy. We can therefore observe the possibility of increased complexity 
of artifacts: from the first arms of obsidian to modern war machines; from the earliest computers to the latest laptop models and so on.

The artifacts, however, include not only material objects but also intangible entities: ideas, worldviews, rituals, social practices, norms, values, and institutions such as a family or a political party. The tendency to entropy or negentropy applies to these institutions as well: a family (considered from a social point of view and not from a biological one) can develop and grow, or dismantle (consider divorce); a family type (such as our nuclear family) may disappear (entropy) or spread throughout the planet (negentropy); a political party or a religion may arise and spread rapidly or exist for decades and disappear in a few years.

We are thus faced with the dual nature of artifacts, which depends substantially on the application or not of individual psychological processes upon them. An artifact is maintained over time, we could say survives and spreads, if it manages to draw upon itself the psychic energy, the cognitive, affective, motivational processes and subsequent actions of individuals: otherwise it tends to disappear from the cultural system.

What matters, in other words, is the relationship between individual psychological selection and cultural evolution, as handled at the beginning of the chapter: the concepts of artifact and the dual nature of artifacts bring forward the fundamental importance of human subjectivity and mental processes in the reproduction and changes of culture, and, conversely, the latter's action in the construction of subjective experience and subjectivity.

The dual nature also applies to complex and intangible artifacts, such as a family, a community, an institution, an ideology, a political system, a legal code, a movement or an artistic style. If I don't take care about an institution or a group to which I belong and I don't participate actively in its activities, if I don't keep my attention and my support to an idea alive, if I don't practice a religion genuinely, if I don't apply or conform to the laws day after day, and if the others too will do the same, all these artifacts will tend to lose meaning and internal information. That group, that idea, that religion, that State with its laws, could possibly disappear, following a direction which we have defined above as entropic. If, on the contrary, we invest our attention, our motivation, our behavior towards those artifacts, then they will remain and will tend to grow, to develop and be transmitted in time, even to future generations: what happens then, is an increase in the complexity of the artifact with a negentropic process. In general terms, this is the basic mechanism for the maintenance of cultures, of their change or, on the contrary, of their eventual disappearance. Culture is transmitted if there is an investment of psychic energy by the people on the artifacts of society and if these can produce positive subjective experience (Csikszentmihalyi, 1990; Gardner, Csikszentmihalyi, Damon, 2001). Artifacts are not produced and maintained by themselves. They are originated from the application of psychic processes of individuals: we actively seek and use an object to achieve personal goals if the relationship with that object allows a good quality of the experience, both from a cognitive and an emotional point of view. An element of culture draws our psychic energy (and 
so it will be adopted and kept) if it gives a good experience. The possibility of having positive states of experience is therefore the basis of the process of cross-generational transmission of human cultures. In this sense, the Flow of consciousness theory has long since taken on a specific significance within the explanatory models of subjective experience (Csikszentmihalyi, 1990; Massimini \& Csikszentmihalyi, 1985; Inghilleri, 1999 Massimini \& Inghilleri, 1993).

\subsection{The Flow of Consciousness}

The experience of Flow of Consciousness conceptualized by Mihaly Csikszentmihalyi (1975, 1990, 1993a, 1997), is also called Optimal Experience. It is a psychologically optimal state from three points of view: from the cognitive perspective as there is the possibility of understanding; from the emotional perspective as there is the possibility of positive emotions; from the motivational perspective as there is the possibility of engagement. This theory, as pointed out above, is optimal also from the point of view of cultural transmission as it highlights the close relationship between the past life of the individual, their motivations, cognitions, current emotions (experienced in the here and now) and the development of material culture and ideas.

As is known, the Flow of Consciousness is a specific state of consciousness that occurs when cognition, emotions and motivation work in an integrated and interactive way, responding to requests from both the outer and the inner world. In the Flow of Consciousness all the psychic energy is invested in the ongoing experience (and thus on the artifacts of culture within that context) and the person experiences a state of competence (resulting from past life), self-determination, meaning and well-being that will lead the person to search the situations, contexts and activities (in other words, artifacts) that allow such positive inner states.

Considering the extensive literature on this theory (see the work of Csikszentmihalyi already mentioned, and among the more recent works, Delle Fave, Massimini \& Bassi, 2011; Engeser, 2012), we shall only briefly describe its main aspects. For the Flow of Consciousness to occur a series of elements must be active simultaneously without conflict between them. These are:

- Concentration and full cognitive activation on the ongoing situation: the irrelevant stimuli disappear from consciousness, all the attention is focused on what is happening at that moment, the cognitive processing of plans for the future or conflict is temporarily suspended.

- Clear goals: the situation is clear, the person knows clearly and without cognitive effort what must be done.

- Immediate feedback: the situation provides feedback and clear signals, allowing the accurate perception of how things are going.

- Absence of self-observation: the individual does not modulate their behavior, as if observing themselves from the outside. 
- Merging between action and awareness: there is a sense of orderly and reversible conscious "fusion" between the Self and the environment.

- Sense of automatic control: perception of being in full control of the ongoing situation; the control is called automatic because it happens without cognitive effort and without self-observation.

- An altered sense of time: time seems to pass more slowly or faster than normal.

- Intrinsic motivation: the experience becomes the reason of the behavior itself; the individual remains in the situation which is fully rewarding in itself: there is a deep sense of motivation and self-determination.

- Balance between challenges and skills: the opportunities for action and the demands of the outer world are perceived as being balanced with the inner capacity available to face them. It should be emphasized that studies subsequent to this original data have shown that the optimal experience arises especially when the balance between challenge and skill is above the subjective mean (Massimini \& Carli, 1988). In other words, the optimal state occurs when the balance is at a higher level than is normally the case for a person in everyday life.

- Absence of boredom: the situation is exciting, allowing the full involvement of one's own potential and of one's Self.

- Absence of anxiety: the situation does not cause stress, conflict or fear; one has the perception of being able to face the outer world with skills and awareness.

- Positive affective state: the person feels good, involved, sociable, with a sense of integration and wholeness.

\subsection{The Influence on Culture and Society}

The experience of Flow influences the processes of development of the individual and the culture in fundamental ways. We have recalled the concept of Cultural Evolution: artifacts, also called memes (Blackmore, 1999; Dawkins, 1976/2006, 1982) as we will discuss in Chapter 10, are the basic units of this evolving, historical, transgenerational process (Inghilleri, 1999). Self-development and cultural evolution are deeply related: the internalization of social values, ideologies, economic and material elements, brings a specific identity, and, on the other side, the everyday behaviors and psychological processes maintain, transmit, and change culture (Berry, Poortinga, Segall \& Dasen, 2002; Csikszentmihalyi, 1993a; Massimini \& Delle Fave, 2000; Stigler, Shweder \& Herdt, 1990). Memes and artifacts that are related with Flow experience and positive emotions can be maintained in the cultures and transmitted to the next generations. That is, people tend to repeat behaviors and search for those elements of culture that allow the Flow of Consciousness as a positive and meaningful experience to the Self. The individual's inner world is thus built around nuclei and cultural practices that have been able to give them meaning and positive experience: the family, the members of the groups to which they belong, the places of everyday 
life, home, school, and work. Society tends to organize itself in order to provide this type of complex and positive experience to the younger generations in the crucial moments of socialization, such as the family and school (Csikszentmihalyi, 1993b; Shernoff, 2013; Shernoff, Csikszentmihalyi, Schneider \& Shernoff, 2003 - see also chapters 8 \& 11).

However, it is necessary to emphasize a key point in order to understand the role of the Flow in the processes of individual and social change. This experiential state represents an ordered, complex and integrated organization of psychic functions. The cognitive processes are active at a high level, the affective state is positive with feelings of well-being and participation, motivation is of an internal type, in the sense of intrinsic motivation (Deci \& Ryan, 1985; Ryan \& Deci, 2000). In this case there is no conflict between the various parts of the psychic apparatus; the inner world responds adequately to the demands of the environment, all the available psychic energy is invested on the action or on the present situation; the subject experiences a sense of self-determination and competence. It is this integrated system of interactions that makes the experience optimal; the phenomenology of the experience itself allows the onset and prolongation of the latter. Therefore, it does not derive mechanically from the experiences and past dynamics, even though it relates to them: it depends, instead, on the original configuration of the psychic organization through which the inner and external needs are combined, creating the possibility of a new behavioral development.

In the relationship between the mind and the social context, the Flow of Consciousness arises as a "proximal" cause of behavior: the experience occurs not only because it meets pre-existing needs (such as the resolution of a conflict or the need to follow social rules passively or in a coercive way), but because its phenomenology is in itself psychologically satisfactory. The Flow is in fact also defined (Csikszentmihalyi \& Nakamura, 1989) as autotelic experience, an ancient Greek word, which derives from auto (self) and telos (goal), and defines an experience or a situation as valid in itself, inasmuch as it is rewarding in itself. The Flow of Consciousness is namely a state that is phenomenologically positive and the situation associated with it is experienced in an optimal way not because it has previously been programmed into our central nervous system or imposed by social rules, but because a specific interaction with the environment allows such an orderly and complex organization of consciousness. It is therefore a psychological state that can be defined as emerging as it is not originated from the genes (biological instructions) or patterns of learned behavior (internalized cultural instructions).

This is an essential theoretical point: on the one hand, the Flow of Consciousness does not arise on an occasional basis. It depends, as we have seen, on past experiences, on the development of adequate skills arising from the continuous relationship with the environment that surrounds us: the environmental challenges are tied to specific cultural contexts and the values, norms, and customs of the society in which we live. The Flow, therefore, depends on culture and society. 
On the other hand being the proximal cause of behavior, it allows freedom of individual thought and creativity (Csikszentmihalyi, 1996). In the interaction between the individual and culture, its symbols, its rules, the individual not only internalizes the behavioral instructions, but also processes, transforms and adapts them to their inner needs. Every person produces more or less significant changes within the symbolic systems and the rules of their culture by directing part of their psychic energy towards symbols or original social purposes; in other words, they can re-interpret values, styles, scientific, religious, moral and political ideas that are presented in a new way and behave accordingly. If these personal re-combinations spread in the cultural system and become part of the latter's structure, they will amount to elements of culture that can be learned and internalized by the following generations. The Flow is therefore a psychological state that is at the heart of the relationship of continuous interaction between the process of psychological selection and that of cultural evolution.

\subsection{Some Connections with Others Theories}

As it always happens in scientific progress, the Flow theory has had its ground-breakers. Csikszentmihalyi himself has highlighted this as from his first work on the subject (Csikszentmihalyi, 1975). A recent review was carried out by Engeser \& Schiepe-Tiska (see Figure 1.1).

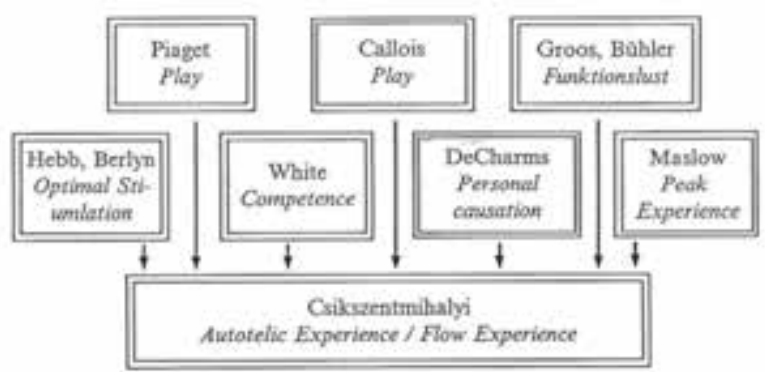

Figure 1.1: Theoretical precursors of Csikszentmihalyi ‘s Flow theory (from Engeser \& Tiska, 2012)

Mentioned below are several other authors who have developed concepts close to the theory of Flow, although starting from a relational and psychosocial perspective.

- A first broad thread is represented by the studies on Empathy ranging from the pioneer reflections of James (1884/2007) to more recent studies in neurosciences (Reiss, 2010). Kohut's idea of empathy as a psychotherapist’s skills (1959/1978) 
will be mentioned here, which will also be useful for Eleonora Riva's reflection in this volume in Chapter 5. Kohut described empathy as vicarious introspection that includes both affective and cognitive capacity to respond empathically to another's emotional and cognitive state. This approach anticipates the one proposed by Gardner (2010) who distinguishes four types of empathy: emotional empathy (mirroring others' feelings), cognitive empathy (alignment of thought), moral empathy (being inspired by moral deeds of others), and physical empathy (when, perhaps via mirror neurons, people mirror others' movements and facial expressions). The state of empathy described by the different authors is accomplished through an experience that can be superimposed on that of Flow: there are indeed challenges/skills balance, intrinsic motivation, attentional focusing, and merging into the situation.

- Another concept is Negative Capability (Bion, 1970). According to Bion, this experiential state is characterized by the ability to tolerate anxiety and fear, to stay in the place of uncertainty in order to allow for the emergence of new thoughts or perceptions. In this sense it is close to the experience of Flow through which the self-confidence of one's own inner capabilities enables the capability to meet the environmental challenges and the creation of new points of view and new opportunities.

- Another type of experience related to Flow is Present Moment highlighted by Stern (2004). Present moment is defined as the intersubjective opportunity for emergent experiences and new understandings in daily life and in the psychotherapy. The experience of the present moment is to a considerable extent involved in selecting and rewriting past memories, foreshadowing the future. The present moments in psychotherapy that bring about change are not conscious (but rather unconscious) and their characteristics are very similar to Flow of Consciousness (Stern, 2004 - see also chapter 5).

- Finally, the concept of Mindfulness (Siegel, 2007). Mindfulness is a flexible state of mind, an openness to novelty, a process of actively planning new perspectives, not reacting to inner experience, acting with awareness, concentration, non-judging of experience. The mindful state is sensitive to context and perspective; the person is situated in the present. When we are mindless, we are trapped in rigid mind-sets, oblivious to context or perspective. When we are mindless, our behavior is governed by rule and routine. In contrast, when we are mindful, our behavior may be guided rather than governed by rules and routines (Langer, 2009).

The last definition, which introduces the theme of the relationship with the social rules, leads us again to emphasize a key point: the positive experiential states, endowed with meaning and optimal for the Self, inevitably open the way to change. Change affects not only the individual, their growth and their development; the experiential states also allow the emergence of new ways of thinking, acting, dealing with 
the social norms and values of the culture. The experience of Flow thus becomes the bridge between individual psychological selection and cultural change. Feeling good inside and feeling psychologically integrated goes hand in hand with our action in the social reality that allows us to transmit the culture to which we belong in a responsible way, but also to innovate it and produce change within.

\section{References}

Berry, J.W., Poortinga, Y.H., Segall, M.H., Dasen, P.R. (Eds.) (2002). Cross-Cultural psychology: research and applications. ( $2^{\circ}$ edition). New York: Cambridge University Press.

Bion W. (1970). Attention and interpretation. London: Tavistock Publications.

Blackmore S. (1999). The Meme machine, Oxford: Oxford University Press.

Bruner J. (1990). Acts of meaning .Cambridge, MA: Harvard University Press

Cole, M. (1996), Cultural Psychology: a once and future discipline, Cambridge: Belknap Press

Csikszentmihalyi, M. (1975/2000). Beyond boredom and anxiety: Experiencing flow in work and play. San Francisco: Jossey-Bass.

Csikszentmihalyi, M. (1982). Towards a psychology of optimal experience, in L. Wheeler (Ed.), Review of Personality and Social Psychology, vol.2, Beverly Hills: Sage.

Csikszentmihalyi, M. (1988). The Flow experience and its significance for human psychology in Csikszentmihalyi M., Csikszentmihalyi I. (Eds.). Optimal experience. Studies on Flow of Consciousness, Cambridge, Mass: Cambridge University Press.

Csikszentmihalyi M. (1990). Flow. The psychology of optimal experience, New York: Harper \& Row

Csikszentmihalyi, M. (1993a), The Evolving Self: a psychology for a third millennium, New York: HarperCollins

Csikszentmihalyi, M. (1993b), L'insegnamento e la trasmissione dei memi, in Massimini F., Inghilleri

P. (Eds.) La selezione psicologica umana. (Human psychological selection). Milano: Cooperativa Libraria IULM

Csikszentmihalyi, M. (1996). Creativity. Flow and the psychology of discovery and invention. New York: Harper Perennial

Csikszentmihalyi, M. (1997). Finding flow. The psychology of engagement with everyday life. New York: Basic Books.

Csikszentmihalyi M. \& Massimini F. (1985). On the psychological selection of bio-cultural information, New Ideas in Psychology, 3, 115-138

Csikszentmihalyi, M., \& Nakamura J. (1989). The dynamics of intrinsic motivation: a study of adolescents. In Research on Motivation in Education, vol. 3, Goals and Cognitions. New York: Academic Press.

Dawkins, R. (1976/2006). The selfish gene. New York: Oxford University Press

Dawkins, R. (1982). The extended phenotype. Oxford: W.H. Freeman \& Co.

Deci E., Ryan R.M. (1985). Intrinsic motivation and self-determination in human behavior, New York: Plenum

Delle Fave A., Massimini F. \& Bassi M. (2011). Psychological selection and optimal experience across cultures. New York: Springer

Engeser S. (Ed.) Advances in flow research, pp 1-22. New York: Springer

Engeser S. \& Schiepe-Tiska A. (2012). Historical lines and an overview of current research on flow, in Engeser S. (Ed.) Advances in flow research, pp 1-22. New York: Springer

Gardner H. (Ed.) (2010). Good Work. Theory and practice. Copyright $\odot 2010$ Howard Gardner for the GoodWork Project. 
Gardner, H., Csikszentmihalyi, M., \& Damon, W. (2001). Good Work: when excellence and ethics meet. New York: Basic Books.

Inghilleri, P. (1999). From subjective experience to cultural change. New York: Cambridge University Press.

Inghilleri P. (Ed.), (2009). Psicologia Culturale. Milano: Raffaello Cortina Editore

James W. (1884/2007) What is an emotion? Radford Va: Wilder Publications

James, W. (1890). The Principles of psychology (2 vols.). New York: Henry Holt (Reprinted Bristol: Thoemmes Press, 1999).

Kahneman D., Diener E. \& Shwarz N. (Eds) 1999. Well-being; The foundations of hedonic psychology. New York: Russell Sage Foundation;

Kohut, H. (1959). Introspection, empathy and psychoanalysis: An examination of the relationship between modes of observation and theory. Journal of American Psychoanalytic Association, 7:459-483. Also in: The Search for the Self (ed.) P. Ornstein (1978). 1:205-232. New York: Int. Univ. Press

Langer E. (2009) Mindfulness Versus Positive Evaluation. In S. J. C.R. Lopez \& Snyder (Eds.), Oxford handbook of positive psychology (279-293). New York: Oxford University Press.

Markus, H.R., Kitayama, S. (1991), Culture and the self: Implications for cognition, emotion, and motivation. Psychological Review, 98, pp. 224-253.

Massimini F. \& Inghilleri P. (Eds.) (1993). La selezione psicologica umana. (Human psychological selection), Milano: Cooperativa Libraria IULM.

Massimini, F. \& Delle Fave, A. (2000), Individual development in a bio-cultural perspective. American Psychologist, 55, pp. 24-33

Monod J. (1971). Chance and necessity. New York: Alfred A. Knopf

Miller J.G. (1970). Living systems. New York: McGraw-Hill

Prigogine I. (1976), Order through fluctuations. Self-organization and social systems, in E. Jantsch, L.H. Waddington (Eds.) Evolution and consciousness: Human systems in transition, Reading MA: Addison-Wesley

Reiss H. (2010) Empathy in medicine. A neurobiological perspective. JAMA, 304(14):1604-5.

Ryan R. M. \& Deci E. L. (2000). Self-determination theory and facilitation of intrinsic motivation, social development, and well-being, American Psychologist, 55, 68-78

Seligman M. \& Csikszentmihalyi M. (2000). Positive psychology: An introduction. American Psychologist, 1, 5-14

Shernoff, D. J. (2013). Optimal learning environments to promote student engagement. New York: Springer.

Shernoff, D. J., Csikszentmihalyi, M., Schneider, B., \& Shernoff, E. S. (2003). Student engagement in high school classrooms from the perspective of flow theory. School Psychology Quarterly, 18, 158-76.

Shweder, R.A. (1991), Thinking through cultures: Expeditions in cultural psychology. Cambridge: Harvard University Press.

Siegel D.J. (2007), The mindful brain: reflection and attunement in the cultivation of well-being. New York, W W Norton \& Co.

Stern D. N. (2004). The present moment in psychotherapy and everyday life. New York: W.W. Norton

Stigler, J., Shweder, R.A., Herdt, G. (1990). Cultural Psychology: The Chicago Symposia. New York: Cambridge University Press.

Vygotskij L.S. (1978). Mind in society. Cambridge, MA: Harvard University Pres 